\title{
PERBANDINGAN SEGMENTASI CITRA PSORIASIS MENGGUNAKAN ALGORITMA K- MEANS CLUSTERING DAN ALGORITMA THRESHOLDING
}

\author{
Witriana Endah Pangesti[1]; Dwiza Riana [2]; Sri Hadianti[3]
}

Pascasarjana Magister Ilmu Komputer

Universitas Nusa Mandiri

witriana21@gmail.com [1]; dwiza@nusamandiri.ac.id[2]; sri.shv@nusamandiri.ac.id[3]

\begin{tabular}{ll}
\hline INFO ARTIKEL & INTISARI \\
\hline Diajukan : & Letaknya kulit pada bagian tubuh manusia berada dibagian luar tubuh \\
05 Agustus 2021 & untuk menyelimuti bagian lain yang ada didalam salah satunya urat atau \\
& lemak, sehingga kulit menjadi salah satu bagian terpenting dalam organ \\
Diterima : & tubuh manusia, karena letaknya di luar maka kulit menjadi rentan untuk \\
17 Agustus 2021 & mengalami penyakit, baik itu penyakin yang berbahaya atau tidak. Contoh \\
& penyakit yang berbahaya untuk kulit manusia adalah penyakit psoriasis. \\
Diterbitkan: & Psoriasis adalah penyakit kulit inflamasi kronis yang ditandai dengan lesi \\
01 Desember 2021 & khas berupa plak, eritematous, dan sisik tebal. Dalam penelitian ini \\
Kata Kunci : & menggunakan dua klaster penyakit psoriasis yaitu klaster Chronic Plaque \\
Psoriasis, K-Means & psoriasis dan Guttate Psoriasis. Dimana dataset yang didapatkan adalah \\
Clustering, GLCM,J48 & dataset public dan selanjutnya masuk pada tahap cropping dan di peroleh \\
Classifier, Thresholding & sebanyak 71 dataset citra psoriasis. Penelitian ini melakukan perbandingan \\
& algoritma antara algoritma k-means clustering dan algoritma thresholding, \\
& dengan pengujian menggunakan hasil nilai dari ektrasi ciri GLCM dengan \\
& meilihat 4 fitur bentuk yaitu contrast, correlation, energy, homogeneity \\
& yang selanjutnya diolah menggunakan aplikasi weka dengan metode J48 \\
classifier dalam menentukan akurasi terbaik dan mendapatkan pohon \\
keputusan. Hasil yang diperoleh adalah k-means clustering merupakan \\
algoritma terbaik dalam mengsegmentasi citra psoriasis yaitu sebesar \\
79\%, dibandingkan algoritma thresholding yaitu sebesar 61\% saja.
\end{tabular}

\section{PENDAHULUAN}

Kulit merupakan salah satu bagian terpenting dalam organ tubuh manusia. Hal ini disebabkan karena kulit berfungsi sebagai organ paling luar yang menutupi hampir seluruh permukaan tubuh, dan melindungi tubuh dari lingkungan hidup sekitar (Damayana, Atmaja and Fauzi, 2016). Namun, karena letaknya pada bagian luar tubuh maka kulit rentan mengalami penyakit, salah satu penyakit yang paling berbahaya adalah Psoriasis

Psoriasis di kategorikan sebagai Noncommunicable Disease (NCD), merupakan penyakit kronis, menyakitkan, menodai dan melumpuhkan dan belum ada obat hingga saat ini sehingga mempengaruhi kualitas hidup yang menderita psoriasis(World Health Organization, 2018). Penyakit ini juga dapat terjadi pada usia berapa pun, dan paling umum pada kelompok usia 50 - 69 tahun. Prevalensi dilaporkan psoriasis di negara berkisar antara 0,09\% dan $11,4 \%$, membuat psoriasis menjadi masalah kesehatan yang serius(World Health Organization, 2018).
Psoriasis adalah penyakit kulit inflamasi kronis yang ditandai dengan plak merah berbatas tegas tertutup skuama tebal sebagai akibat dari gangguan proliferasi dan diferensiasi epidermis(Damayanti, 2018). Psoriasis vulgaris ditandai dengan lesi khas berupa plak, eritematous, dan sisik tebal yang terdistribusikan dengan tendensi simetris(Damayanti, 2018).

Chronic plaque psoriasis akan terlihat sebagai area kulit yang kecil hingga besar, berbatas tegas , merah, bersisik dan menebal. Ini kemungkinan besar mempengaruhi bagian tubuh di siku, lutut, dan punggung bagian bawah tetapi mungkin akan timbul pada bagian tubuh mana pun. Psoriasis guttate adalah varian dengan onset akut plak eritematosa kecil. Ini biasanya mempengaruhi anak-anak atau remaja, dan sering dipicu oleh infeksi streptokokus grup-A tonsil. Sekitar sepertiga dari pasien dengan psoriasis guttate akan mengembangkan psoriasis plak sepanjang masa dewasa mereka (Rendon and Schäkel, 2019)

Teknik kompresi citra merupakan suatu teknik yang digunakan untuk merepresentasikan citra melalui pengurangan 
kualitas pada citra asli, namun tetap mempertahankan informasi. (Raharja and Harsadi 2018). Supaya Supaya pengguna dapat dengan nyaman menyimpan maupun mentransmisikan citra tanpa ada masalah seperti lambat mentransfer citra maupun error saat mengirim citra. Maka pada penelitian ini bertujuan bagaimana mengkompresi citra dengan membandingakan metode Lossy compression pada penelitian sebelumnya dengan metode Lossless compression yang penulis lakukan untuk mengetahui metode mana yang paling baik dalam pengurangan ukuran citra.

\section{BAHAN DAN METODE}

Pada Penelitian ini adalah penulis melakukan perbandingan metode dalam mensegmentasi citra psoriasis. Tahapan awal yang peneliti lakukan adalah meresize citra menjadi ukuran 100 x 100 pixcel, selanjutnya citra yang akan di bagi menjadi 2 yaitu testing dan training. Citra yang masuk dalam data training selanjutnya masuk ke tahapan konversi

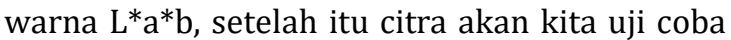
pada masing-masing algoritma segmentasi. Tahapan selanjutnya setelah citra tersegmentasi citra akan masuk ke tahap ekstrasi citri dengan metode GLCM, setelah mendapatkan ciri dari masing-masing citra, peneliti melakukan klasifikasi dengan J48 classifier decission tree. Setelah didapatkan pohon keputusan maka peneliti selanjutnya mengimplentasikan segemntasi terbaik pada matlab. Adapun alur penelitian yang diajukan dapat dilihat pada Gambar 2.

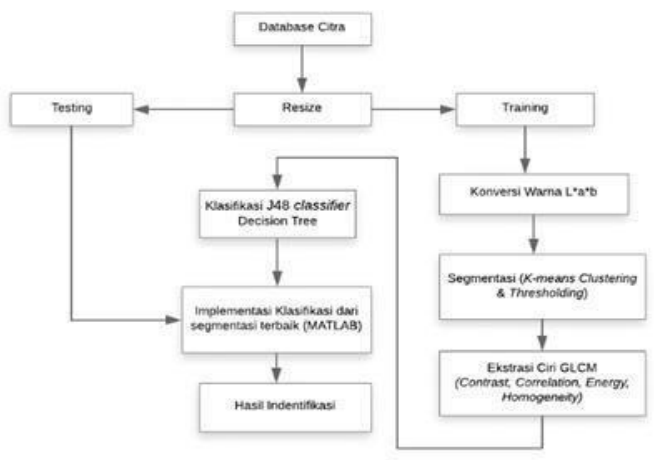

Gambar 1. Model Desain Penelitian

\section{HASIL DAN PEMBAHASAN}

\section{Resize}

Setelah di dapatkan citra asli dengan ukuran 294 x 222 pixcel, maka penulis merubah ukuran citranya menjadi 100x100 pixcel agar citra menjadi lebih mudah untuk di proses. Dan di dapatkan sebanyak 71 citra psoriasis menjadi database penelitian.:

\section{Konversi warna $L^{*} a^{*} b$}

Tahapan selanjutnya adalah konvesi warna dari citra asli memeiliki ruang warna RGB menjadi ruang warna $L^{*} a^{*} b$ untuk kedua algoritma yang penulis bandingkan. Berikut Gambar 3. contoh hasil konversi warna.

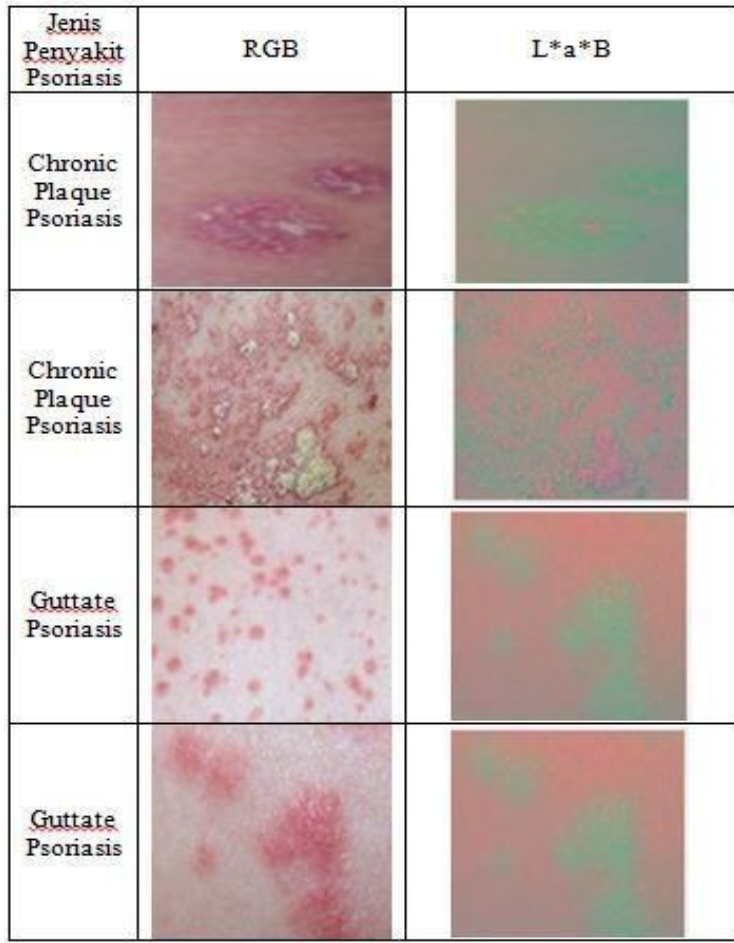

Gambar 2. Konversi Citra RGB menjadi L*a*b

\section{Data Training dan Testing}

Setelah dilakukan pengumpulan database citra dan merubah ukuran citra, selanjutnya citra dipilih menjadi dua data, yaitu data training dan data testing. Dataset yang digunakan untuk data training sebanyak $60 \%$ yaitu sebanyak 43 citra, dengan kombinasi antara citra Psioriasi dengan kategori Chronic Plaque Psoriasis dan kategori Guttate Psoriasis. Selain data training, ditentukan juga untuk data testing sebanyak $40 \%$ yaitu sebanyak 28 citra. Tabel 1 menjelaskan beberapa contoh citra yang digunakan. 


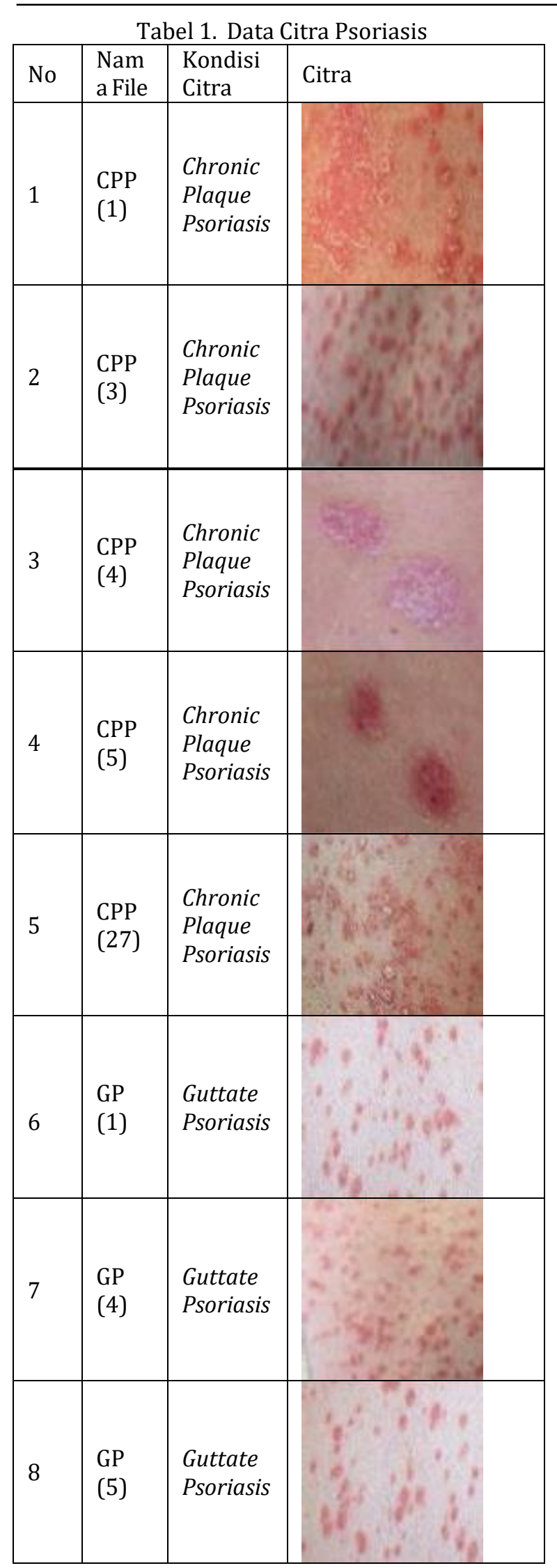

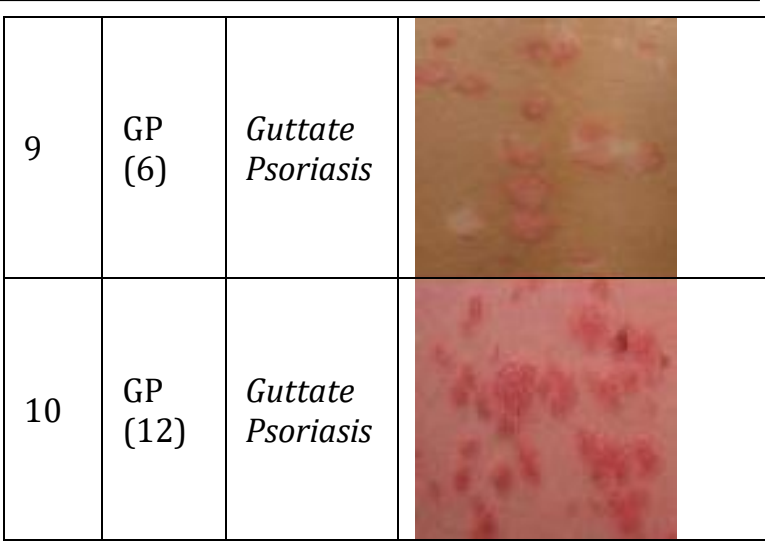

VII. Segementasi Algoritma K-Means Clustering dan Segmentasi Algoritma Thresholding

Setelah dilakukan konversi ruang warna dari RGB menjadi L*a*b maka selanjutnya adalah mensegmentasi. Segmentasi ini mengcluster warna-warna yang ada pada citra berdasarkan kedekatan warnanya sehingga daerah yang terkena psoriasis akan tersegmentasi. Contoh bisa dilihat pada tabel 2 .

Tabel 2. Contoh Segmentasi Algoritma K-Means Clustering

\begin{tabular}{|c|c|c|c|}
\hline $\begin{array}{c}\text { Jenis } \\
\text { Penyaki } \\
\mathrm{t} \\
\text { Psoriasi } \\
\text { s }\end{array}$ & RGB & $L^{*} a^{*} b$ & $\begin{array}{l}\text { K-Means } \\
\text { Clustering }\end{array}$ \\
\hline $\begin{array}{c}\text { Chro } \\
\text { nic } \\
\text { Plaqu } \\
e \\
\text { Psori } \\
\text { asis }\end{array}$ & & & \\
\hline $\begin{array}{c}\text { Chro } \\
\text { nic } \\
\text { Plaqu } \\
e \\
\text { Psori } \\
\text { asis } \\
\end{array}$ & & & \\
\hline $\begin{array}{c}\text { Gutta } \\
\text { te } \\
\text { Psoria } \\
\text { sis }\end{array}$ & & & \\
\hline $\begin{array}{l}\text { Gutta } \\
\text { te } \\
\text { Psoria } \\
\text { sis }\end{array}$ & & & \\
\hline
\end{tabular}


Pada Tabel 2 diatas dapat dilihar perubahan dari citra awal yang merupakan ruang warna RGB kemudian dikonversi menjadi ruang warna $\mathrm{L}^{*} \mathrm{a}$ b lalu disegmentasi daerah yang memiliki penyakit dengan metode k-means, daerah psoriasis ditunjukan dengan bagian yang lebih cerah dengan area lain berwana hitam.

Tabel 3. Contoh Segmentasi Algoritma Thresholding

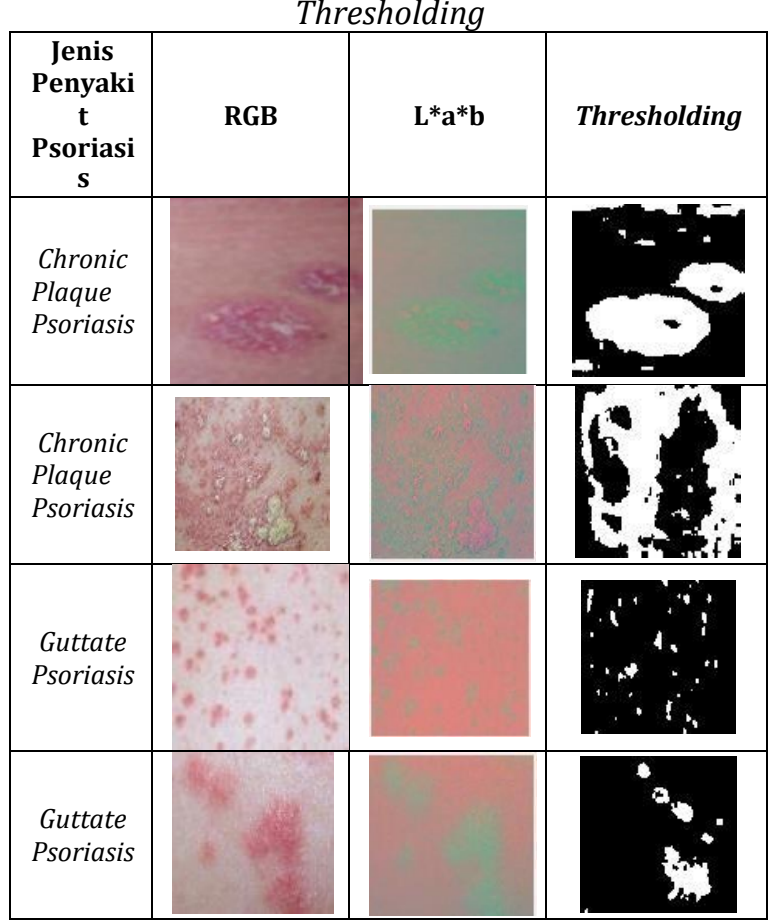

Pada Tabel 3. dapat kita lihat juga perbedaan ruang warna yang terjadi dari citra asli yang memiliki ruang warna RGB di konversi menjadi ruang warna $L^{*} a * b$ lalu disegmentasi daerah penyakit psoriasisnya dengan menggunakan metode thresholding. Daerah yang mengalami penyakit psoriasis ditunjukan dengan warna hitam putih yang melingkar pada area penyakit.

\section{Ekstrasi Citri GLCM (Gray level Co-Occurrence Matrix)}

Selanjutnya dilakukan analisis tekstur menggunakan metode GLCM (GrayLevel Cooccurrence Matrix) untuk mengeluarkan nilainilai dari 4 fitur yaitu Contrast, Correlation, Energy, Homogeneity pada setiap citra dalam data training yang telah berhasil tersegmentasi guna mencari metode mana yang paling baik sehingga mendapatkan rule klasifikasi untuk di tuangkan pada aplikasi matlab.

\section{Hasil Klasifikasi Segmentasi Terbaik}

Akurasi
Data Training yang sudah proses analisis tekstur menggunakan metode Gray level CoOccurrence Matrix (GLCM), selanjutnya diolah kembali menggunakan metode decision tree j48 classifier dengan, sehingga menghasilkan nilai akurasi untuk masing-masing algoritma yang dibanding dan menghasilkan model klasifikasi yang terbaik dari akurasi algoritma yang paling tinggi. Pembentukan model klasifikasi di Implementasikan kedalam WEKA. Berikut dijelaskan Gambar 3 Hasil akurasi k-means clustering dan Gambar 4 Hasil Akurasi threshold.

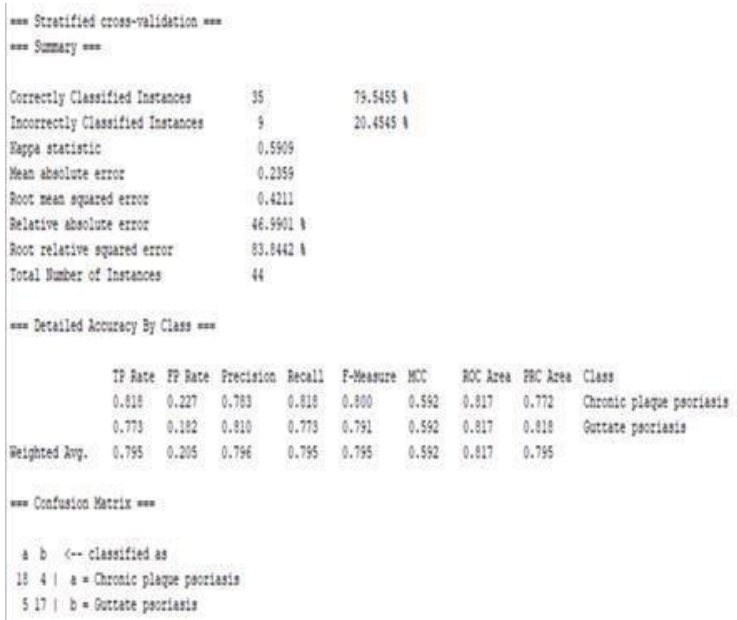

Gambar 3 Hasil Akurasi K-Means Clustering

Dari Gambar 3 diatas bisa kita lihat dari 44 citra yang kita hitung nilai klasifikasi akurasi terdapat 35 data citra yang benar terdeteksi dengan akurasi sebesar 79\%, dan data yang tidak berhasil terklasifikasi ada sebanyak 9 citra psoriasis.

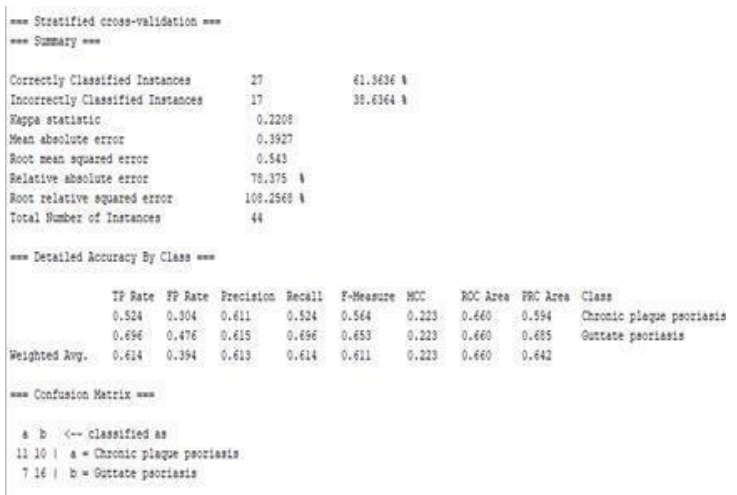

Gambar 4 Hasil Akurasi threshold

Dari Gambar 4 diatas bisa kita lihat dari 44 citra yang kita hitung nilai klasifikasi akurasi terdapat 27 data citra yang benar terdeteksi 
dengan akurasi sebesar $61 \%$, dan data yang tidak berhasil terklasifikasi ada sebanyak 17 citra psoriasis.

Sehingga dari perbandingan kedua metode dengan menghitung klasifikasi akurasi diatas algoritma K-means clustering sebesar 79\% sedangkan algoritma thresholding sebesar $61 \%$. Dan penulis menyimpulkan diantara kedua metode terpilihlah metode $\mathrm{k}$-means clustering untuk selanjutnya dilihat pohon keputusan untuk menentukan citra psoriasis itu termaksud dalam klaster Chronic plaque psoriasis atau klaster Guttate psoriasis.

Berikut Gambar 5 Adalah hasil pohon keputusan k-means clustering.

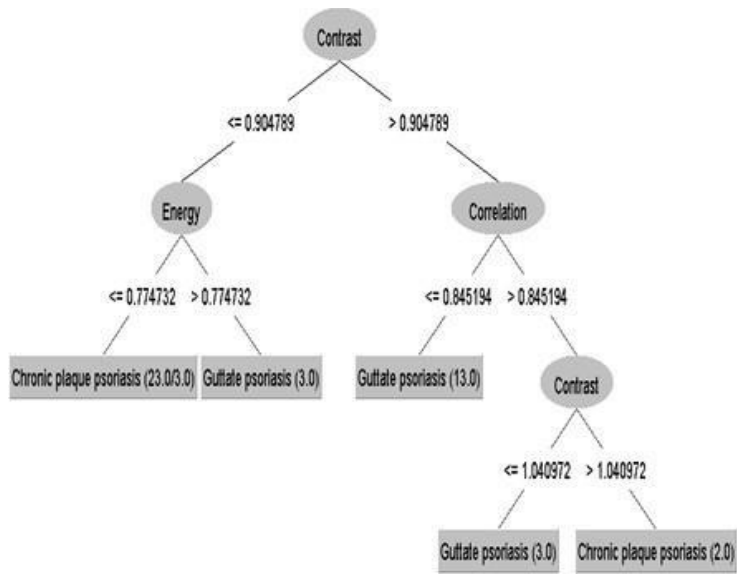

Gambar 4.6 Pohon Keputusan Decision Tree J48 Classifier

\section{Implementasi dan hasil}

Gambar yang terletak dibawah ini merupakan hasil implementasi rule penelitian dengan menggunakan algoritma k-means clustering yang dibuat dalam bentuk GUI. Gambar 6 merupakan tampilan dari program yang telah dibuat.

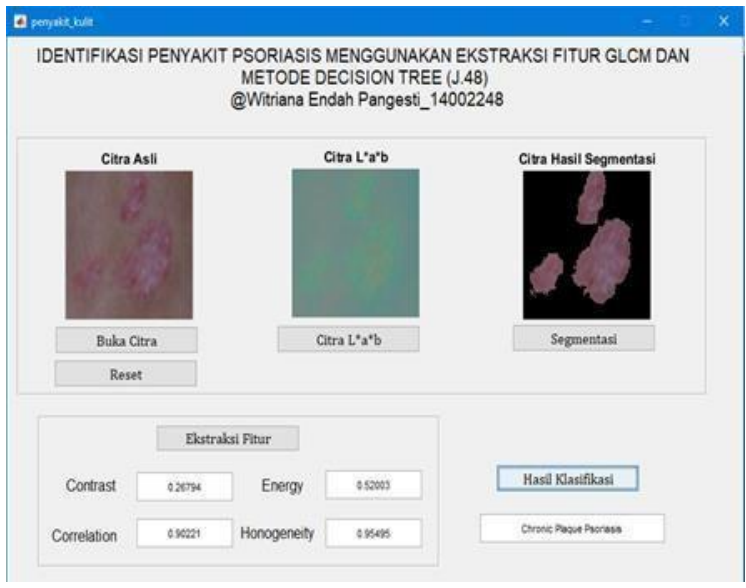

Gambar 6. Form Klasifikasi
Pada Gambar 6 merupakan form klasifikasi yang telah penulis buat untuk pengujian algoritma k-means clustering dalam segmentasi dan mengklasifikasi citra psoriasis. Dimana terdapat menu buka citra dimana berfungsi untuk mengambil citra yang diinginkan untuk klasifikasi, kemudian ada menu citra $L^{*} a * b$ ketika di klik berfungsi untuk mengkonversi ruang warna citra yang semula ruang warna RGB menjadi ruang warna $L^{*} a^{*} b$.

Selanjutnya terdapat menu segmentasi, ketika menu ini di klik maka citra yang telah masuk konversi ruang warna, selanjutnya di lakukan proses pengsegmentasi dengan algoritma k-means clustering guna mencari wilayah mana yang merupakan wilayah terdapat penyakit psoriasis. Selanjutnya terdapat menu ekstrasi fitur ketika di klik maka akan menghasilkan data-data pixcel dari hasil GLCM. Selanjutnya terdapat menu hasil klasifikasi jika di klik maka akan keluar hasil dari citra yang kita pilih apakah termaksud jenis penyakit chronic plaque psoriasis atau guttate psoriasis.

\section{KESIMPULAN}

Dengan metode analisis tekstur Gray Level Co-occurrence Matrix (GLCM) citra psoriasis yang telah tersegmentasi dapat dicari nilai teksturnya. Fitur - fitur contras, correlation, energy, dan homogeneity berhasil dimunculkan sebagai nilai yang terkandung pada setiap citra.

Perbandingan antara algoritma kmeans clustering dan algoritma thresholding dengan cara mencari akurasi terbaik berhasil di dapatkan melalui metode decision tree j48 classifier dari nilai GLCM dengan pengimplementasi menggunakan weka dan didapatkan akurasi yang terbaik adalah metode k-means clustering dengan nilai akurasi sebesar 79\% dibandingkan algoritma thresholding hanya $61 \%$ saja.

Rule dari pohon keputusan decision tree classifier berhasil diimplementasikan pada GUI Matlab guna untuk mencari klaster citra psoriasis dengan tepat. 


\section{REFERENSI}

Damayana, I., Atmaja, R. D. and Fauzi, H. (2016) 'Menggunakan Wevelet Transform Detection of Skin Cancer Melanoma Based on Digital Image', Deteksi Kanker Kulit Melanoma Berbasis Pengolahan Citra Menggunakan Wevelet Transform, 3(3), pp. 4718-4723.

Damayanti, K. D. P. (2018) 'Profil Psoriasis Vulgaris di RSUD Dr. Soetomo Surabaya : Studi Retropektif ( Psoriasis Vulgaris : A Retrospective Study J', Berkala IImu Kesehatan Kulit dan Kelamin - Periodical of Dermatology and Venereology, 30(3), pp. 248-254.

Rendon, A. and Schäkel, K. (2019) 'Psoriasis pathogenesis and treatment', International Journal of Molecular Sciences, 20(6), pp. 1-28. doi: 10.3390/ijms20061475.

World Health Organization (2018) 'NCDs Noncommunicable diseases and their risk factors', Who, (1), pp. 1-4. Available at: https://www.who.int/ncds/en/\%0Ahttp:// www.who.int/ncds/en/.

Agarwal, S. (2014) Data mining: Data mining concepts and techniques, Proceedings - 2013 International Conference on Machine Intelligence Research and Advancement, ICMIRA 2013. doi: 10.1109/ICMIRA.2013.45.

Astuti, T. et al. (2016) 'Penerapan Algoritme J48 Untuk Prediksi', Jurnal Telematika, 9(2), pp. 1-10.

Febrinanto, F. G., Dewi, C. and Wiratno, A. T. (2018) 'Implementasi Algoritme K-Means Sebagai Metode Segmentasi Citra Dalam Identifikasi Penyakit Daun Jeruk', Jurnal Pengembangan Teknologi Informasi dan Ilmu Komputer (JPTIIK) Universitas Brawijaya, 2(11), pp. 5375-5383.

Hayat, N. M., Prasetijo, A. B. and Septiana, R. (2019) 'Analisis Kinerja Algoritma J48 Decision Tree untuk Pengambilan Keputusan Beli/Jual pada Saham PT Harum Energi Tbk. (HRUM)', JTIM : Jurnal Teknologi Informasi dan Multimedia, 1(3), pp. 244-253. doi: 10.35746/jtim.v1i3.43.

Kristiani, Febe Sintia., Anggraini, D. I. (2020) 'Psoriasis Pustulosa Generalisata : Tinjauan Kasus Pada Geriatri Generalized Pustulosa Psoriasis : Case Report on a Geriatric', Medula, 9(4), pp. 692-698.
Kusuma, A. W. and Ellyana, R. L. (2018) 'Penerapan Citra Terkompresi Pada Segmentasi Citra Menggunakan Algoritma K-Means', Jurnal Terapan Teknologi Informasi, 2(1), pp. 65-74. doi: 10.21460/jutei.2018.21.65.

Lumbansiantar, D. S. (2019) 'Analisa Data Bencana Alam Untuk Prediksi Dampak Yang Ditimbulkan Dengan Algoritma J48 (Studi Kasus : Palang Merah Indonesia)', KOMIK (Konferensi Nasional Teknologi Informasi dan Komputer), 3(1), pp. 25-29. doi: 0.30865/komik.v3i1.1562.

Pham, D. H. and Meignen, S. (2018) 'A Novel Thresholding Technique for the Denoising of Multicomponent Signals', ICASSP, IEEE International Conference on Acoustics, Speech and Signal Processing - Proceedings, 2018April(April), pp. 4004-4008. doi: 10.1109/ICASSP.2018.8462216.

Puspasari, N. et al. (2019) 'Kadar Dopamin Plasma Yang Tinggi Merupakan Salah Satu Faktor Risiko Terjadinya Psoriasis Vulgaris', 50(1), pp. 27-31. doi: 10.15562/Medicina.v50i1.180.

Rizal1, Reyhan Achmad Suardin Gulo1, Octavriana Della C. Sihombing1, Ardi Bernandustahi Miduk Napitupulu1, Amsal Yusuf Gultom1, T. J. S. (2020) 'ANALISIS GRAY LEVEL COOCCURRENCE MATRIX (GLCM) DALAM MENGENALI CITRA EKSPRESI WAJAH Reyhan', 3(January), pp. 31-38.

Setiawan, I. et al. (2019) 'Pengolah Citra Dengan Metode Thresholding Dengan Matlab R2014A', Jurnal Media Infotama, 15(2), pp. 65-70.

Sinaga, K., Buulolo, E. and Nadeak, B. (2019) 'Implementasi Algoritma Decision Tree_J48 untuk Memprediksi Resiko Kredit pada Koperasi Simpan Pinjam (Studi Kasus : Kofipindo Lubuk Pakam)', KOMIK (Konferensi Nasional Teknologi Informasi dan Komputer), 3(1), pp. 20-24. doi 10.30865/komik.v3i1.1561.

Tunggorono, H. (2017) 'Aplikasi Pendeteksi Kelayakan Telur Menggunakan Metode Backpropagation dan Thresholding', Psikologi Perkembangan, (2330-1425), pp. 54-63. doi: 10.1017/CB09781107415324.004.

Widodo, R., Widodo, A. W. and Supriyanto, A. (2018) 'Pemanfaatan Ciri Gray Level Co- 
Occurrence Matrix ( GLCM ) Citra Buah Jeruk Keprok ( Citrus reticulata Blanco ) untuk Klasifikasi Mutu', Jurnal Pengembangan
Teknologi Informasi dan Ilmu Komputer, 2(11), pp. 5769-5776. 